\title{
Jax Warrior Lover: la perfecta unión de lo erótico y lo distópico
}

\author{
Ana Rubio Jiménez \\ Universidad de Sevilla \\ anamariarj96@gmail.com \\ https://dx.doi.org.10.12795/futhark.2018.il3.07
}

Fecha de recepción: II.02.2018

Fecha de aceptación: 15.04.2018

Resumen: Jax Warrior Lover es el inicio de una saga de libros de la autora alemana Inka Loreen Minden. Bajo este pseudónimo escribe novelas eróticas, aunque en el caso de la saga Warrior Lover, entremezcla erotismo y distopía creando un género original y novedoso al que podríamos denominar erotismo distópico o distopia erótica. En esta primera entrega encontramos una crítica a la sociedad, pero también una novela romántica con un alto grado de pornografía para llegar a un público más amplio. En el siguiente trabajo se diseccionan las partes más importantes que caracterizan este género dentro de la obra.

Palabras clave: distopía, erotismo, novedoso, género, novela.

\section{Jax Warrior Lover: the perfect union of eroticism and dystopia}

\begin{abstract}
Jax Warrior Lover is the beginning of a book series written by the German author Inka Loreen Minden. Under this pseudonym she writes mostly erotic novels, although in the case of the Warrior Lover saga, she mixes eroticism and dystopia creating an innovative genre that we could call dystopian eroticism or erotic dystopia. In this first installment we find a social critique, but also a romantic novel with a high degree of pornography to reach a wider audience. In the following essay we dissect the most important parts that characterize this new genre within Inka's work.
\end{abstract}

Key words: dystopia, eroticism, innovative, genre, novel. 


\section{Introducción}

Inka Loreen Minden es el pseudónimo que usa Monika Dennerlein' para escribir la maravillosa serie titulada Warrior Lover ${ }^{2}$. Jax es la primera entrega, en la que nos demuestra con éxito cómo pueden unirse el erotismo ${ }^{3}$ y la distopía ${ }^{4}$ para crear casi un nuevo género que podríamos llamar erotismo distópico o distopía erótica ${ }^{5}$, según nos queramos centrar en una cosa u otra.

\footnotetext{
I Autora alemana de literatura erótica y adolescente. Tiene tantos pseudónimos que sus seguidores la llaman 'the multi-named woman' (la mujer de los mil nombres). Su marido piensa a veces que Inka es más un alien que un humano, porque cambia fácilmente su forma de ser. Otros pseudónimos que utiliza son: Lucy Palmer, Mona Hanke (para novela erótica), Loreen Ravenscroft (para el género Romantasy, es decir, novela romántica y de ficción) y Monika Davis. Vid. https://www.goodreads.com/author/show/3003450.Inka_Loreen_Minden.
}

${ }^{2}$ A Jax le siguen las siguientes novelas pertenecientes a la misma serie de Warrior Lover: Crome (20I3), Ice (20I3), Storm (20I3), Nitro (20।4), Andrew (20I4), Steel (20I4), Fury (20I6), Tay (20I6), Shadow (20I7), Flame (2017) y Verox (2017).

${ }^{3}$ En esta obra podemos apreciar tanto erotismo como pornografía, es decir, sexo explícito y sexo usado como adorno y escenario del mundo distópico que se nos presenta: "Digámoslo desde el principio: no hay gran literatura erótica, lo que hay es erotismo en grandes obras literarias. Una literatura especializada en erotismo y que no integre lo erótico dentro de un contexto vital es una literatura muy pobre. Un texto literario es más rico en la medida en que integra más niveles de experiencia. Si dentro de ese contexto el erotismo juega un papel primordial, se puede hablar verdaderamente de literatura erótica. La Celestina, por ejemplo, es una obra maestra, probablemente la más importante de la literatura española después del Quijote. Decir que La Celestina es una obra erótica sería empobrecerla, porque, aunque es eso, también es muchas otras cosas: una obra de una gran riqueza verbal, de una gran inteligencia en su construcción, que incluye muchas manifestaciones de la vida -la moral, la cultura, la psicología-, pero indudablemente el erotismo tiene en ella un papel primordial." (Vargas Llosa 200I),

4 “Andreu Domingo sostiene [...] que la distopía «ejecuta el retrato de los monstruos engendrados por la razón». Retrato donde contemplamos (bajo la rúbrica de «si no cambiamos las cosas este será el infierno sobre la tierra que aguarda a nuestros descendientes») un porvenir deshumanizado, desnaturalizado y opresor que reproduce al detalle los tópicos recurrentes de las utopías preponderantes. Ello se explica en la medida en que «la diferencia entre la utopía y la distopía es sólo axiológica, pero no material; lo que cambian son los juicios de apreciación del sujeto del discurso no los contenidos del texto». En otras palabras; la distopía es el irónico doppelgänger de la utopía, o si se quiere, una utopía contada por un absoluto disidente de ésta." (Martorell 20I2: 275-276).

${ }^{5}$ No son pocas las obras distópicas en las que encontramos un elemento erótico, aunque es raramente destacable o perceptible sin un previo análisis profundo: "En variadas obras que tienen como centro a los autómatas como "El hombre de arena" y "Las Hortensias" en literatura y en el cine Metrópolis, El hombre manos de tijeras y El hombre bicentenario, como ejemplos más bien obvios, se repite un tema aún no analizado por la crítica en la narración de Holmberg: la tensión erótica del relato. Por tensión erótica me refiero a que hay en ciertos personajes - uno humano, el otro, máquina- un deseo de poseer uno/a a otro/a. Normalmente, estos personajes son protagónicos. El deseo no es una sublimación que encuentra resolución por vías no sexuales, sino que busca concretarse en el aquí y ahora del relato. Sin embargo, la resolución de este deseo se da en una tensión y no en una relación fluida porque el relato demarca 
Esta obra ofrece un mundo devastado, típico de cualquier distopía, parecido al que se plantea en Mad Max ${ }^{6}$. La protagonista, Samantha Walker, que narra los hechos en primera persona, nos muestra sus preocupaciones y repugnancia hacia este mundo en el que tan solo sobrevive; ya no hay sitio para vivir. Se trata de un régimen autoritario ${ }^{7}$ en el que los forasteros ${ }^{8}$ no son bienvenidos. Ella era médica, pero tras la muerte de uno de los soldados que protegen de la ciudad, se la acusa y se le da a elegir su sentencia. En este mundo se castiga de dos formas': o escoges una inyección letal para desaparecer del mapa para siempre, o accedes a que tu

zonas de conflicto alrededor de un mismo objeto pretendido por dos sujetos diferentes, formando así un triángulo amoroso: Horacio-Hortensia-María; Olimpia-Nataniel-Clara; Edward Scissorhands-Peg-Jim, y en este caso, Hermann (Hipknock)-Luisa-Horacio (Fritz)." (Martín 2012: 260).

$6 \mathrm{II}$ argue that this post-apocalyptic landscape is an expression of two converse impulses: the terrifying contemplation of the empty space of the world after a nuclear war, and the exhilaration that this blank canvas is the stage for treats of adventure and heroism." (Williams 2005: 30I).

7 “Aun en el año 2014 seguimos siendo testigos y partícipes de una sociedad caótica: del mismo modo en que las tribus nativas fueran sometidas y erradicadas, y los planetas y satélites entraron a la carrera por ser monopolizados y conquistados, el mundo contemporáneo sigue siendo organizado y guiado por sociedades de control, ya sea con ayuda de una efímera promesa del placer y la felicidad o por la imposición del dolor y el totalitarismo [...] Vemos así la evolución del concepto de distopía desde lo literario, el cual reflejará un paso de lo social a lo personal: no solo se presenta el sistema totalitario, sino que se enfoca en el individuo, concretamente en el joven, el cual representará al consumidorconsumido. La figura del joven tomará aún más fuerza con los fenómenos literarios distópicos del siglo $\mathrm{XXI}$, que con sagas como Los Juegos del Hambre refuerzan aún más el ideal del género distópico como un reconocimiento del caos y de la pérdida indefinida del paraíso perseguido por la utopía." (Roa Devia 2014: 75-77).

${ }^{8}$ Los forasteros son vistos como enemigos. Podríamos extrapolarlo a los problemas actuales que se viven con los inmigrantes y refugiados que llegan a otros países huyendo de la miseria del suyo propio. Los países que están más desarrollados tienen miedo de que acaben con sus recursos, a pesar de no ser estos precisamente escasos. Vid. https://elpais.com/cultura/2017/05/08/actualidad//494264276_5450 94.html; "Un sentimiento de derrota se ha apoderado de la perspectiva de criticidad de la conciencia colectiva ante la guerra y la pobreza: el racismo, la xenofobia, el genocidio, el apartheid, el hambre, la miseria, la indignidad de la condición humana. Una barbarie que se hizo conocida ante los ojos de todos en el siglo $X X$ fraguada en estas dos guerras mundiales que parecen no tener fin. Las guerras de la civilización, las guerras culturales del racismo, de las que con tanta lucidez nos hablara Foucault, sus consecuencias, su retórica de odio y muerte al "otro" aún siguen latentes y presentes en nuestra cultura geopolítica. El concepto de raza no es étnico. Es una resistencia a lo que no es conocido, maleable, adiestrado, sometido: el otro ajeno. Esconde una necesidad de control y para ello en el proceso de producción social se inventa -y se realiza- al bárbaro y la categoría de raza, y la retórica de la amenaza, del miedo, del terror y con ella la idea de la necesidad apremiante de "defensa". El discurso xenófobo de algunos líderes europeos de la actualidad pulula en el mismo caldo de las guerras de la raza de nuestra era." (Sáez de lbarra 2008).

9 "Y es que la visión distópica del futuro humano en cuyos terrores se deleita el autor, sirve principalmente para alertar sobre un mal creado por el propio ser humano. La distopía revela el castigo que ocurrirá si no se remedia el mal, a través de la visión de la humanidad futura y su sociedad (o cuando menos, de la separación radical entre "los buenos" y “los malos")." (Tirado 2018). 
cuerpo se convierta en mercancía. Se trata, por tanto, de un régimen de castigo punitivo, no de reinserción ${ }^{10}$. No se pretende que el individuo corrija sus errores, sino que se le elimina del sistema. Samantha opta por la vía de la cosificación. Ahora es tan solo una esclava sexual ${ }^{\prime \prime}$ : tiene un número de serie y un código de barras tatuado en su brazo. Ha dejado de ser una persona'2. Ya no es Samantha.

Nos encontramos ante un mundo en el que sigue habiendo una palpitante lucha de clases $^{13}$; las personas con un intelecto superior se distinguen del resto. Estas personas, supuestamente superiores, pueden optar por trabajos mejores, dedicados al régimen (podía tratarse de abogados, médicos...), y están separados de aquellos que no poseen tanta capacidad intelectual ${ }^{14}$. Samantha pertenecía a esa "clase superior" y ahora se encuentra por debajo de todas las clases: es una

${ }^{10}$ Interesa el sufrimiento de todo individuo que el sistema considere que ha errado: "Se pregunta: ¿Cuál es el fin político de las penas? Inspirar terror a los demás hombres. En otro lugar insiste: el fin que procura la pena es separar con el terror a los otros hombres del delito." (García Ramírez 2000: 4I).

"No sería esta la primera distopía en la que nos encontramos ante esclavas sexuales. La serie de HBO "The Handmaid's Tale" es una distopía en la que no encontramos elementos futuristas, pero sí una sociedad en la que la ciencia no ha avanzado y los valores humanos han retrocedido unos cientos de años: "Basada en la novela «El cuento de la criada», de Margaret Atwood, Premio Príncipe de Asturias de Las Letras en 2008, en lugar de imaginar la sociedad del futuro como una más avanzada gracias a la tecnología, esta distopía la representa como una más conservadora y represiva, fundamentalista, en el que el Estado, teocrático y fascista, recupera los valores puritanos y combate la infertilidad esclavizando sexualmente y adoctrinando a «las criadas», esas mujeres que deben dar a luz a los hijos de sus gobernantes o ser castigadas." (Cabanelas 2017).

${ }^{12} \mathrm{Al}$ igual que en otras obras distópicas se cuestiona la humanidad de los robots o la falta de humanidad en los humanos, como se refleja incluso en obras audiovisuales tan recientes como Detroit: Become Human, en este caso, ya que no hay robots o máquinas de inteligencia artificial como en otras novelas, la esclavización sexual pone de relieve la renuncia a la humanidad y el paso a la cosificación de la persona.

13 La lucha de clases está presente en muchos relatos y obras distópicas: "En El huésped (The Host, 2006) señala los riesgos de la contaminación ambiental y la manipulación mediática y gubernamental, y en El expreso del miedo (Snowpiercer, 2013) nos muestra un futuro postapocalíptico, en donde hemos acabado con el hábitat humano, pero no con la lucha de clases y otras taras sociales que perviven en un tren de alta velocidad que viaja alrededor de un mundo congelado.” (Loaiza 2017: 298).

${ }^{14}$ En las distopías siempre se intenta clasificar al ser humano siguiendo unos criterios que le hagan olvidar la esencia de lo que significa precisamente ser humano. Ya sea por intelecto, raza, género, posición privilegiada... El ser humano siempre encuentra un motivo para hacer la guerra. Por ejemplo, un tema de actualidad es la lucha por los derechos de la mujer. Siempre se ha considerado que, por motivos biológicos, la mujer era menos apta que el hombre. A pesar de que se han conseguido muchos avances, todavía hoy se teme que estos derechos por los que tanto se ha luchado se pierdan: "En su nueva novela Hazards of Time Travel, que se publicará en noviembre, Joyce Carol Oates adopta un enfoque casi literal para explorar el temor a que la lucha por los derechos de la mujer esté en retroceso. La novela comienza en un futuro Estados Unidos autocrático, donde se enseña a los estudiantes que los hombres tienen un coeficiente intelectual mayor al de las mujeres, y se centra en una joven que es arrestada por traición tras cuestionar el régimen escolar. De castigo, la teletransportan al estado de Wisconsin en 1959 para que sea "reeducada" y se vuelva más dócil." (Alter 2018). 
esclava ${ }^{15}$. A pesar de su situación de sierva, es muy crítica con todo lo que ve a su alrededor: está presenciando la depravación en su máxima expresión ${ }^{16}$.

Jeder macht es mit jedem, es gibt kaum feste Beziehungen. Treue und

Vertrauen sind Fremdwörter geworden, das erschreckt mich. (Minden 2003)

Aquí es donde entra el componente erótico, magistralmente enlazado con el planteamiento distópico. La descripción de los personajes, tanto de los guerreros que violan a las esclavas, como la de estas últimas, prioriza el físico con un toque lascivo ${ }^{17}$. Los hombres son fuertes, musculosos, fieros, muestran actitud soberbia y predomina en ellos la sicalipsis ${ }^{18}$. La sangre reseca en sus cuerpos o la suciedad en sus torsos, lejos de provocar repulsión, son elementos que actúan como afrodisíaco sobre las féminas ${ }^{19}$. Evoca la figura del gladiador ${ }^{20}$. Las mujeres, que solo

15 "[...] el esclavo constituía un escalón más de la pirámide social, el más bajo, el último que llegaba a desligarse de su condición humana para incluirle en el ámbito de las bestias domésticas." (Peña Tristán: 2012)

${ }^{16}$ Es el sistema político el que determina cómo vivirá y se comportará la sociedad. En casos de formas de gobierno autoritarias o déspotas, es fácil caer en la depravación: "De un lado, al identificar la sociedad como origen y fundamento del mal y establecer la bondad consustancial a la naturaleza humana, Rousseau daba réplica a la antropología de Hobbes. De otro lado, al identificar el orden político defendido por Hobbes en el Leviatán (y que no es otro que el despotismo) como el orden característico de la etapa histórica en que el género humano habría alcanzado la cima de su depravación, Rousseau acometía la crítica directa de la doctrina política hobbesiana.” (López 2006: 165).

17 Casi como un embrujo parecido al que usan las vampiresas para conquistar a sus víctimas, la lascivia juega aquí el mismo papel: nubla el juicio de las presas sexuales, haciéndoles desear los cuerpos de sus depredadores y, por ende, el castigo y sufrimiento disfrazado de placer que esto conlleva: "Aparecerán de nuevo toda la seducción y la lascivia de Lucilla para conquistar a la víctima. El sentimiento de amor/odio volverá a atrapar a Gonzalo: «con ella sólo caben dos sentimientos: el rechazo total o la atracción irresistible; dicho de otro modo, el amor o el odio"." (Agustí 2012).

18 "Significa «picardía o malicia referente a temas sexuales». Este vocablo fue formado arbitrariamente por yuxtaposición de las palabras griegas sykon (higo) y aleipsis (frotar, untar), con base en alguna idea que dejamos librada a la imaginación del lector. Decimos arbitrariamente porque la palabra no nos llegó, por cierto, desde el griego, sino que fue creada arbitrariamente por publicitarios hace más de un siglo y aparece por primera vez en 1902, en el anuncio de una obra pornográfica en el diario El Liberal de Madrid. El uso más frecuente no es sicalipsis, sino el adjetivo sicalíptico, cuyo significado, más allá de la significación académica reseñada al comienzo, es 'obsceno' o 'pornográfico'." (Soca 20l0); En la Odisea de Annabelle (2017) de Rebeca Rader ya aparecen unidos los términos distopía y sicalipsis, que se entrelazan "como dos serpientes mitológicas copulando y luchando al borde del abismo", en este caso, para crear una historia oscura, llena de rabia y erotismo oculto, donde el sexo está prohibido y es un instrumento de control social.

${ }^{19}$ Los elementos que refuerzan la masculinidad del hombre, en este caso, tan solo provocan un mayor deseo sexual de las esclavas hacia ellos. Si son fieros en la batalla, dan a entender que también serán de tal manera en la cama.

${ }^{20}$ Nos recuerda a la figura del guerrero manchado de sangre y arena, musculoso y feroz, símbolo de virilidad. Posee el típico cuerpo de deportista de élite. Con la serie Espartaco, se creó un método con el $\begin{array}{ll}\text { Futhark I3 (2018) } & 109\end{array}$ 
llevan un hilo de tanga y una tela fina para cubrir sus pechos, poseen, en general, prominentes senos y nalgas redondeadas ${ }^{21}$. La importancia recae en la escasez de ropa sobre ellas ${ }^{22}$.

A pesar de tratarse de un régimen autoritario, se tiene en cuenta la homosexualidad. También hay siervos masculinos y es tratado con naturalidad ${ }^{23}$. Como en cualquier futuro distópico, habría de existir un avance ${ }^{24}$ : las enfermedades venéreas han sido erradicadas y no hay forma de que se produzcan embarazos involuntarios ${ }^{25}$. Es la cuna del hedonismo en su estado más puro: Coitus gratia coitus $^{26}$.

mismo nombre que permitía a los hombres entrenar hasta convertir sus cuerpos en unos de talla $\mathrm{XXL}$, de esos que hacen explotar las camisetas cuando se las prueban porque están hiperdesarrollados. Vid. Humbert 2010.

21 "Siempre ha habido motivos ocultos detrás de cada prototipo de belleza: si se quiere incrementar el índice de la natalidad el ideal de belleza se forma con caderas anchas y pechos grandes; si se quiere ostentar la condición de clase social dominante se muestra la gordura en tiempos de hambruna o crisis; si se quiere mostrar cuidado de la imagen, selección de alimentos, exaltación de la juventud y tiempo libre para cuidarse físicamente se muestra un cuerpo con unas dimensiones de $90-60-90$ con cabellos rubios y aspecto frágil, o cuerpos delgados, casi infantiles; si se quiere mostrar dinamismo, fortaleza física, aventuras y exploraciones varias se presenta un cuerpo más musculoso y una tez más curtida". (Pérez Parejo 2006).

${ }^{22}$ La ropa que pronuncia las formas femeninas e insinúa — pero no enseña - lo que hay debajo es lo que se considera sensual: "Warwick decía que lo realmente sexy era sugerir, no enseñar." (Lee 20I I).

${ }^{23}$ Ya en las sociedades antiguas existían las relaciones homosexuales y eran vistas con normalidad, aunque esto significaba una degradación de la mujer: "La mujer no tenía ninguna influencia sobre la vida intelectual y moral, e incluso las consideradas como libres no podían participar en la vida pública. Al estar tan degradada, como en la mayoría de las sociedades antiguas, el placer que podía dar al hombre también se degradó, pues en realidad era un ser inferior. Las relaciones heterosexuales fueron consideradas, como dice González Duro, como una experiencia poco ennoblecedora, casi como una necesidad puramente biológica. El hombre sólo podía tener en estas condiciones unas relaciones sexuales de mayor calidad a través de la relación homoerótica, en la que podía, por medio del amante elegido, «apreciar racionalmente la belleza»." (García Valdés 1981: 19).

${ }^{24}$ Todos estos avances intentan, por lo general, hacer que el individuo abandone su libre pensamiento: "Fire Captain Beatty, the novel's chief book-burner, explains that "technology, mass exploitation, and minority pressure carried the trick" of suplanting independent thought with conformity and leading to censorship" (McGiveron 1996: 245-256).

25 El preservativo no solo se utiliza para evitar los embarazos no deseados. El problema de las enfermedades venéreas está a la orden del día: "[...] la profilaxis de las enfermedades venéreas compartió la agenda de preocupaciones oficiales con otros temas como el tratamiento de la tuberculosis o la reducción de los índices de mortalidad infantil y el estímulo de la natalidad a través de la protección de la madre y el niño." (Biernat 2007: 26I-262).

${ }^{26}$ Adaptación de la expresión latina Ars gratia artis, que significa "el arte por la gracia del arte", "el arte por el arte mismo" o, más comúnmente, "el arte por el arte”, es un principio de la estética idealista (desde Immanuel Kant y su Crítica del juicio de 1970) que implica el individualismo y la libertad del arte, libertad artística o libertad del artista, paralela a la libertad de expresión definida como una de las 
No es algo que se oculte, el sexo ha dejado de ser un tema tabú y todo está enfocado a é $\left.\right|^{27}$. Hay cámaras que graban los encuentros sexuales, las violaciones son algo divertido de ver, las mujeres del público gritan “¡Fóllame!” o “ ¿Escógeme a mí!" cuando aparece un soldado canon ${ }^{28}$. Nos encontramos ante una suerte de pornografía estatal: la sociedad aclama esa pornografía ${ }^{29}$, pero desconoce lo que hay detrás y no le interesa el sufrimiento que entrañan dichas violaciones ${ }^{30}$. En

libertades proclamadas por la revolución liberal o revolución burguesa. La expresión inglesa art for art's sake (atribuida a Edgar Allan Poe) y la francesa l'art pour l'art (atribuida a Victor Cousin y a Benjamin Constant de Rebecque) tienen un uso similar. La expresión francesa fue divulgada posteriormente por Théophile Gautier al utilizarla como lema del parnasianismo, para sugerir que no hay conexión entre arte y moralidad. Vid. https://es.wikipedia.org/wiki/Arte_por_el_arte; Sugiero con esto que tampoco hay en la obra conexión aparente entre el sexo y la moralidad. El sexo tiene lugar por el simple hecho de disfrutar del acto sexual, sin más complicaciones.

${ }^{27}$ Una sociedad sana es educada sexualmente para evitar que el sexo sea un tabú o el eje de todo individuo: "A lo largo de la historia, la sexualidad se ha vivido de muchas maneras distintas. Ha habido periodos de cierta liberación sexual, junto con otras épocas más puritanas. Hoy en día, vivimos en un momento donde el sexo representa un papel extraño. A pesar de la liberación sexual acontecida en las últimas décadas, todavía encontramos la sexualidad como un tema incómodo en ciertos contextos. Ahora bien, a pesar de seguir presentándose como un tabú, nos encontramos referencias al sexo por todas partes. Desde la publicidad a las conversaciones privadas de un grupo de amigos, el sexo sería ese fantasma que está y no está en todos los sitios. [...] Que el sexo en la sociedad se vea como un tabú, sobre todo en la familia o en la educación, tiene graves consecuencias. A lo largo de nuestra vida, este va a tener su propio papel, tanto a nivel de desarrollo biológico como social. Si tratamos la sexualidad como algo incómodo y lo ignoramos, vamos a caer en déficits de educación sexual. Una educación que necesita de un diálogo honesto y abierto. La educación sexual cimienta a lo largo del crecimiento de un individuo una manera de vivir saludablemente su sexualidad." (Sanfeliciano 2018).

28 "El ideal de belleza masculino destaca la importancia del ejercicio físico para conseguir el arquetipo, como había hecho el mundo clásico de Grecia, de modo que la estatura superior a la media, el cabello abundante, la frente ancha, los pómulos prominentes, la mandíbula marcada, las extremidades y el tronco levemente musculosos, la espalda ancha y las piernas largas y deportivas no difieren excesivamente del canon propuesto por el Discóbolo de Mirón, salvo quizá por unos pequeños detalles como lo de los pómulos y las mandíbulas, que en Grecia eran más redondeados y en la actualidad se prefieren más tipo Robocop o Terminator, probablemente debido a la influencia de la robótica y la cibernética." (Pérez Parejo 2006).

29 "Los materiales sexualmente explícitos presentan algunas ventajas como permitir a algunas personas enriquecer su vida sexual [...]. También se han reportado algunas desventajas como el hecho que han reducido a la mujer a un objeto de placer y la reducción de las relaciones sexuales a sólo un acto físico ajeno al contexto de una relación. Asimismo, reduce nuestra corporalidad y sexualidad a la genitalidad y finalmente lleva a la creación de estereotipos." (Vera-Gamboa 2000: 78).

30 " [...] existe un contrato sexual previo al contrato social, un contrato que instaura la ley del derecho sexual de los hombres sobre las mujeres. La pornografía es uno de los instrumentos de perpetuación de dicho contrato. Mediante ella, no sólo se movilizan representaciones degradantes del cuerpo de las mujeres, sino que se construye lo que es una mujer; una cosa al servicio sexual de los hombres." (Prada 2010: II).

Futhark I 3 (2018) 
palabras de Anthony Burgess ${ }^{31}$, estaríamos ante un caso de ultraviolencia ${ }^{32}$. De nuevo, la autora vuelve a enlazar, casi sin darnos cuenta, el erotismo con la sociedad distópica.

La protagonista, al igual que el resto de mujeres en su situación, observa la escena con terror ${ }^{33}$ :

Das Volk ist live dabei, sitzt gemütlich zu Hause vor den Screenern und holt sich einen runter. Sie widern mich an. Alles widert mich an. (Minden 2003)

Esta novela no solo está dirigida a "amas de casa desesperadas" 34 , como se decía de 50 Sombras de $\mathrm{Grey}^{35}$, sino que cualquier mujer u hombre podrían sentirse identificados con la protagonista, especialmente personas de éxito laboral que

\begin{abstract}
${ }^{31}$ Autor de "A Clockwork Orange” (en español La naranja mecánica), obra de la que luego Kubrick haría una película homónima, dotándola de su toque personal: "Ambientada en un decadente e impreciso futuro cercano, narraba las extremas barbaridades cometidas por una pandilla de jóvenes delincuentes $y$ el brutal e innovador tratamiento de regeneración al que será sometido su líder (sensacional y emblemática interpretación de Malcolm McDowell) por parte de las instituciones sociales y carcelarias. A través de una fascinante textura visual y un conglomerado de secuencias tan agresivas como espeluznantes, aunque en gran parte justificadas, Kubrick parodiaba la corrupción política, la hipocresía social o la arbitrariedad del poder establecido hasta alcanzar una satírica representación de la amoralidad hedonista y destructiva, que mantuvo totalmente íntegra pese a las fuertes presiones de la censura." Vid. https://diccineario.com/2015/I I/09/ultraviolencia-la-naranja-mecanica/.
\end{abstract}

32 Término que se aplica a actos de extrema violencia, a menudo sin justificación y con víctimas escogidas al azar. Representa "la violencia por la violencia", entendiéndola casi como un deporte. Este término fue introducido por el escritor Anthony Burgess en su novela 'La naranja mecánica', de 1962. En ella el protagonista Alex DeLarge se dedica a cometer actos violentos con gran saña y crueldad, hasta incluir el asesinato, sin ninguna finalidad aparente y sin que sienta ningún remordimiento por ello. Vid. https://es.wikipedia.org/wiki/Ultraviolencia.

${ }^{33}$ Vive en un sistema en el que se busca infundir terror a aquellos que "han ido contra la ley": "Ahora bien, si se extremara la visión utilitarista de la pena, quizá desembocaría en los peores castigos. Serían los peores, en un sentido, porque se propondrían causar una impresión devastadora: terror." (García 2000: 4I).

${ }^{34}$ En cuanto al público que aclama 50 Sombras de Grey: "Según datos editoriales, el grueso del público lector está integrado por amas de casa que pospusieron sus carreras y objetivos profesionales, e invirtieron todo su tiempo y energía en ser esposas y madres. Más allá de que sueñen con las prácticas sadomasoquistas, es probable que las páginas liberen el deseo subconsciente de experimentación dentro del matrimonio. Quizás sacuda sus vidas sexuales, ahogadas por los quehaceres y las preocupaciones del día a día." (Labandal 20I5).

35 La obra tuvo, por lo general, un buen recibimiento, pero también recibió bastantes críticas por su pobreza literaria y por los lectores que disfrutaban de ella: "Many critics refer to the series as "mommy porn", alongside jokes about the poor literary quality of the novels. This reveals a disdainful attitude toward fans of the franchise, who are often dismissed as bored, borderline illiterate housewives." Vid. http://theconversation.com/the-mommy-porn-myth-who-are-the-fifty-shades-of-grey-fans-37649. 
buscan escapar de su rutina y fantasear con la idea de ser sumisas ${ }^{36}$. Es más frecuente que entre los lectores se encuentren mujeres, pero el hecho de que la autora haya decidido también darle mención a la homosexualidad hace que la obra sea más inclusiva ${ }^{37}$.

La protagonista siente que ella no corresponde al $\operatorname{canon}^{38}$, y no entiende por qué se encuentra entre las "presas" que sí que cumplen con ese físico prototípico:

Hoffentlich gefalle ich keinem von ihnen. Zumindest entspreche ich nicht dem gängigen Schönheitsideal, habe keinen Korrekt-Maß-Körper. (Minden 2003)

Por regla general, todos tenemos inseguridades ${ }^{39}$. El lector logra sentir, de esta manera, empatía hacia Samantha y meterse en el pape ${ }^{40}$. Podría decirse que hasta busca una especie de catarsis $^{41}$ : somos personas normales y corrientes, pero

\begin{abstract}
${ }^{36}$ Las lectoras de 50 Sombras de Grey, como se nombra en la nota a pie de página número 34, buscan también escapar de sus agotadoras rutinas como madres y esposas. En este caso, con la serie Warrior Lover, se busca escapar de una rutina de éxito laboral. Llegamos a la conclusión de que cualquier rutina nos estresa, y la literatura está ahí para darnos esa vía de escape que necesitamos, aunque solo sea por unas horas.

${ }^{37}$ La autora ha escrito también obras "homoeróticas” como Gaylüste (2012) o Sundhäfte Küsse (20I6).

38 “En la obra El desnudo femenino, Linda Nead propone tesis interesantes sobre la construcción de éste y entre ellas podemos señalar el carácter de materia, de materia que construye el autor y la mirada masculina. El cuerpo femenino es masa que el artista modela, diseña, encaja en un canon, mide y juzga. El artista, el publicitario y el supuesto observador masculino, a quien se dirige. En permanente estado de horizontalidad, de segundo plano, de inferioridad visual, es utilizada para agrandar la presencia masculina, su poder y su capacidad de decisión. Es, como hemos dicho, la coartada a través de la cual, como en un espejo de aumento, la presencia del sujeto masculino se ve aumentada." (López, Gauli 2000).
\end{abstract}

39 Son los propios individuos los que incrementan con ese canon autoimpuesto las inseguridades femeninas en este caso: "El canon de belleza describe una mujer que no siente, no piensa y no expresa, un canon mucho más cercano a una muñeca que a un ser con vida. El cuerpo es el soporte comunicativo más extendido universalmente a lo largo de la historia. Es el medio identificativo y con el que mejor se empatiza, el mejor gancho comercial para hacerlo objeto de deseo y focalizador de todas las miradas. El consumidor quiere el cuerpo que le vende el cine, la publicidad, la televisión, internet... quiere ese cuerpo perfecto que tan lejos está del suyo. Los mass media nos venden el cuerpo como campo de trabajo hacia la perfección. Falsas soluciones que actúan de sugestión para el consumidor enmascarando una realidad inajustable a esos cánones de belleza imposibles." (Barbaño, Muñoz 2017).

${ }^{40}$ La identificación con el personaje es importante: “Investigaciones como las de Igartua nos confirman que gran parte del disfrute generado por las películas a sus audiencias es resultado de la identificación con los personajes." (Bermúdez 2010); En el blog Libros and stuff se preguntó a los seguidores con qué personajes literarios habían sentido identificados: https://librosandstuff.blogspot.com/2015/05/identificado-personaje-literario-.html.

41 “ [...] Men usually show more sexual fantasies than women, its content being characterized as active (i.e., they imagine doing something to their partner), impersonal (i.e., multiple partner), and directed towards domination; meanwhile, women usually present more passive fantasies (i.e., they imagine something being done to done by their partners), favor intimate/romantic contents, and present more submission fantasies." (Saramago, Cardoso 2017: 87I).

Futhark I 3 (20 |8) 
también ansiamos que alguien, a quien consideramos superior por poseer aquello que a nosotros consideramos que nos falta, se fije en nosotros y nos aporte pasión, una historia de amor... algo de chispa a la vida. También hace que, en un mundo caótico, como es el que se nos presenta en esta distopía, no nos sintamos culpables por desear una vía de escape, en este caso, una persona exitosa, generalmente mujer, que sueña con un poco de sumisión. Permite que no reprimamos nuestras más oscuras fantasías sexuales ${ }^{42}$.

El personaje de Samantha se nos muestra humano, con miedos e inseguridades ${ }^{43}$, inquietudes. Nos deja ver en todo momento la evolución de sus sentimientos hacia Jax, que para ella es totalmente misterioso. Mezcla elementos de acción desenfadados con un enfoque trágico y una trama amorosa que no nos dejará indiferentes.

En resumen, se trata de una novela polivalente $y$ ahí reside su riqueza literaria: puede ser crítica, sátira, pornografía ${ }^{44}$ e historia romántica. Todo a la vez.

\section{Referencias bibliográficas}

Bibliografia primaria

BuRgeSS, A. (1995), A Clockwork Orange. W. W. Norton \& Company.

JAMES, E.L. (20I2), Fifty Shades of Grey. Vintage Books.

Minden, I. L. (20I3), Jax - Warrior Lover. CreateSpace Independent Publishing Platform.

(2013), Crome - Warrior Lover. CreateSpace Independent Publishing Platform.

(20I3), Ice - Warrior Lover. CreateSpace Independent Publishing Platform.

. (20I3), Storm - Warrior Lover. CreateSpace Independent Publishing Platform. . (20I4), Nitro - Warrior Lover. CreateSpace Independent Publishing Platform.

42 Lo que también conocemos como fetiches. "La palabra fetiche viene del portugués fetisso o feitizo y significa, como dice Littré, objeto feérico y por esa razón, venerado.” (Pouillon 1975: 2).

${ }^{43}$ Vid. Nota 39. Nos muestra una chica con cuyas cualidades podríamos sentirnos identificados.

44 "En pulcra entrada del diccionario, pornografía es «la cualidad de los escritos que excitan morbosamente la sexualidad»." (Zavala 1983: 509); "La pornografía, y en concreto la literatura pornográfica, ha sido y aun es una de las parcelas más denostadas de toda actividad crítico-didáctica en clave literaria. Infravalorada, criticada, olvidada y siempre temida, constituye uno de los más evidentes olvidos del ámbito de la Crítica Literaria y la Didáctica de la Literatura en el Estado Español. Juzgada como una práctica literaria menor, carente de valor y considerada, en todo caso, como discurso pseudoliterario; la literatura pornográfica representa, no obstante, uno de los reflejos con mayor originalidad del arte literario: no en vano está hecha para incitar, para excitar y para soliviantar los ánimos de lectores y lectoras." (Pardo de Neyra 2017: 447). 
(2014), Andrew und Emma - Warrior Lover. CreateSpace Independent Publishing Platform.

. (20I4), Steel - Warrior Lover. CreateSpace Independent Publishing Platform. (2016), Fury - Warrior Lover. CreateSpace Independent Publishing Platform. . (20I6), Tay - Warrior Lover. CreateSpace Independent Publishing Platform. (2017), Shadow - Warrior Lover. CreateSpace Independent Publishing Platform.

(2017), Flame - Warrior Lover. CreateSpace Independent Publishing Platform.

(20I7), Verox - Warrior Lover. CreateSpace Independent Publishing Platform.

OATES, J. C. (20I8), Hazards of Time Travel. Harper Collins.

POE, E. A. (2008), The Poetic Principle. Quill Pen Classics.

RADER, R. (2017), La odisea de Annabelle. Versión Kindle.

\section{Bibliografia secundaria}

AGUSTÍ, C. (20I2), La creación del arquetipo de la vampiresa en la literatura gótica anglosajona y su evolución en la literatura juvenil española actual: Carmilla y Visita de tinieblas. Universidad Católica de Valencia San Vicente Mártir. Polifonía. 53.

Alter, A. (2018), “Las nuevas autoras de la distopía feminista”, The New York Times. Recuperado de: https://www.nytimes.com/es/2018/10/I I/feminismoficcion-distopial.

Barbaño, M., Muñoz-Muñoz, A. M. (2017). La construcción de la imagen de las mujeres: net.art y medios de comunicación. Historia y Comunicación Social, 22, I, 252-253.

BeRMúdEZ, S. (2010). Las emociones y la teoría literaria. Un encuentro enriquecedor para la comprensión del texto literario. En-claves del pensamiento, 4, 8. México.

Biernat, C. (2007). Médicos, especialistas, políticos y funcionarios en la organización centralizada de la profilaxis de las enfermedades venéreas en la Argentina (1930-1954). Anuario de estudios americanos, 64(I), 257-288.

CABANELAS, L. M. (2017). The Handmaid's Tale: Hacia una sociedad fascista: La distopía en la que los coches no vuelan pero las criadas son esclavas sexuales. $\quad A B C$ Play Series. Recuperado de: https://sevilla.abc.es/play/series/criticas/abci-hacia-sociedad-fascistadistopia-coches-no-vuelan-pero-criadas-esclavas-sexuales20170426005I noticia.html.

Domingo, A. (2008). Descenso literario a los infiernos demográficos. Distopía y población. Barcelona: Anagrama.

GARcía, S. (2000), Estudio Introductorio. Beccaria: el hombre, la circunstancia, la obra. Fondo de Cultura Económica. 
García, A. (198I), Historia y presente de la homosexualidad. Akal Editor. Madrid.

HumberT, H. (20l0). Ahora, si quieres, puedes llegar a tener el cuerpo de un gladiador como Espartaco. Trendencias Hombre. Recuperado de: https://www.trendenciashombre.com/fitness/ahora-si-quieres-puedesllegar-a-tener-el-cuerpo-de-un-gladiador-como-espartaco.

LABANDAL, F. G. (20I5). 50 sombras de Grey: análisis de un best seller", Infobae. Recuperado de: https://www.infobae.com/2015/06/15/1735397-50sombras-grey-analisis-un-best-seller/

LADEVEZE, L. (1985). De la utopía clásica a la distopía actual. Revista de Estudios Políticos, 44, 47-80.

LEE, M. (20II). Un hombre indómito. Editorial Harlequin Ibérica, S.A. Madrid.

LOAIZA, M. (20I7). Okja una fábula distópica o «cuando el destino nos alcance», Universidad de Colima, 1958, 297-302.

López, M., GaUli J. C. (2000). El cuerpo imaginado. Revista Complutense de Educación, II, 2, 43-57.

LÓPEZ, A. D. (2006). La Sociedad y el Miedo: Una interpretación onto-social de la teoría política de Jean-Jacques Rousseau. Revista de Estudios Políticos, I31, $14 \mid-166$

MARTín, I. (20I2). Eduardo Holmberg: erotismo y ciencia ficción. V Congreso Internacional de Letras, 260. Facultad de Filosofía y Letras, UBA.

MARTORELL, F. (2012). Notas sobre dominación y temporalidad en el contexto postmoderno a propósito de la distopía. Astrolabio. Revista internacional de filosofia, I3, 274-286.

McGiveron, R. O. (1996). What "Carried the Trick"? Mass Exploitation and the Decline of Thought in Ray Bradbury's Fahrenheit 45I. Extrapolation, 37(3), 245-256.

PARDo de NeYRA, X. (2017). Literatura y Pornografía vs. Erotismo y Literatura: Hacia una semiótica de la obscenidad. UNED Revista Signa, 447-467.

PeÑA, M. L. (20I2). La esclavitud en la literatura española de los Siglos de Oro. Tesis Doctoral, Universidad Complutense de Madrid.

PéreZ, M. (20I7). Cortina: «Lo que molesta de los inmigrantes es que sean pobres». El País, Madrid. Recuperado de: https://elpais.com/cultura/20 I7/05/08/actualidad/I494264276_545094.html.

PÉreZ, R. (2006). El canon de belleza a través de la Historia: un método de descripción de personas para alumnos de E/LE. Espéculo: Revista de Estudios Literarios, 34.

POUILLON, J. (1975). Fetiches sin Fetichismo. Bibliothèque d'Anthropologie.

PRADA, N. (20I0). ¿Qué decimos las feministas sobre la pornografía? Los orígenes de un debate. La manzana de la discordia, 5, I, 7-26. 
ROA, C. L. (2014). Distopía y literatura: De 1984 de George Orwell a Los juegos del hambre de Suzanne Collins. Trabajo de Grado. Pontificia Universidad Javeriana. Bogotá.

SÁEZ, M. B. (2008). Distopía. Museo de Arte de la Universidad Nacional de Colombia.

SANFELICIANO, A. (20l8). ¿El sexo en la sociedad es un tabú o una obligación? La mente es maravillosa. Recuperado de: https://lamenteesmaravillosa.com/elsexo-en-la-sociedad-es-un-tabu-o-una-obligacion/.

Saramago, M., Cardoso, J. (20I7). Wilson's sex fantasy questionnaire: Portuguese validation and gender differences. Psicologia, Saúde \& Doença, 18, 870-879.

TIRADO, A. (2018). Distopías y terrores para un mundo real. Opinión Médica.

VARGAS LlOSA, M. (200I). Mario Vargas Llosa: «Sin erotismo no hay gran literatura». El País, Testimonios recogidos por Javier Rodríguez Marcos. Recuperado de: https://elpais.com/cultura/2016/I0/27/babelia//4775627/5_7863 I8.html.

VERA-GAMBOA, L. (2000). La pornografía y sus efectos: ¿Es nociva la pornografía?. Revista Biomédica, I I (I), 77-79.

Williams, P. (2005). Beyond Mad Max III: Race, Empire, and Heroism on PostApocalyptic Terrain. Science Fiction Studies, 30I-3I5.

Zavala, I. M. ( 1983). Inquisición, erotismo, pornografía y normas literarias en el siglo XVIII. Anales de Literatura Española, 2, 509-529.

\section{Webgrafia}

https://www.goodreads.com/author/show/3003450.Inka_Loreen Minden (última vez consultado el 18/12/2018)

https://es.wikipedia.org/wiki/Arte_por_el_arte (última vez consultado el 18/12/2018)

https://diccineario.com/2015/II/09/ultraviolencia-la-naranja-mecanica/ (última vez consultado el I8/I2/20/8)

https:/www.fundeu.es/noticia/la-palabra-del-dia-sicalipsis-572I/ (última vez consultado el 18/12/20/8)

http://theconversation.com/the-mommy-porn-myth-who-are-the-fifty-shades-ofgrey-fans-37649 (última vez consultado el 18/12/20/8)

https://librosandstuff.blogspot.com/2015/05/identificado-personaje-literario-.html (última vez consultado el 19/12/20/8) 
